\title{
Science Communication Models for Agricultural Transformation in Uganda
}

\author{
Tibasaaga, A. ${ }^{1}$, Zawedde, B. M. ${ }^{1, *}$ \\ ${ }^{1}$ National Agricultural Research Organization, Uganda. \\ *Corresponding author. (6)+256772206237 (C) bmugwanya@gmail.com
}

\begin{abstract}
This paper focuses on the models of science communication used to promote and support use of agricultural research outputs in Uganda. It also explores quasi-novel approaches of making agricultural research more visible to end-users through strategic communications and extension models that are hoped to increase adoption rates in Uganda. Surveys, literature review and key informants were used to evaluate the communication efforts by the National Agricultural Research Organisation (NARO) - the apex body for agriculture research in Uganda. The findings indicated that $31 \%$ of respondents perceived NARO as a source of poor products and services. This has resulted in distrust, which is largely attributed to use of ineffective models of communication used in the past. Different approaches of communication and extension are proposed as flagship models that can be implemented through NARO's projects, private extension partners and, in some cases, through partnership with the National Agricultural Advisory Services (NAADS). These communication and outreach strategies can improve understanding of the technologies, and consequently influence adoption of NARO technologies for improvement of the agricultural sector.
\end{abstract}

Keywords: Agricultural research, Extension, NARO Uganda, Outreach

\section{INTRODUCTION}

Research in agriculture in Uganda dates back to 1898 when the Entebbe botanical gardens were established to test adaptability of commercial crops like Arabica coffee, rubber, sugarcane, cocoa and cotton to the Ugandan soils (NARO, 2017). In 1922, the first experiment station was opened while in 1937 a Research Division was established in the Department of Agriculture (Laker-Ojok, 1994). In 1949, the Cotton Research Corporation opened a regional research station at Namulonge that is now called the National Crops Resources Research Institute (NaCRRI). During the period of 1950 to1962, research efforts mainly focused on coffee and cotton to provide raw materials for the industries in Britain and the rest of Europe.

The period after independence in 1962 ushered in a new wave of agricultural initiatives aimed at staying the tempo of agricultural research for national development. Research stations were established to food crops like cassava, sesame and soybeans to compliment cash crops (NARO, 2017). The late 1990s and the post millennium period saw a pivotal change in government policies towards agricultural research and innovations knowledge transfer. Due to the failure of industry to raise the economic status of many African countries, there was a "rediscovery of agriculture's potential for poverty eradication and environmental 
sustainability" in Uganda and a number of other African countries (Mwangombe et. al. 2001). This changed the position and contribution of agricultural research in national priorities and development agenda. In 1992, the National Agricultural Research Organisation was established, by an Act of Parliament, as a national body to oversee, coordinate, and drive the agricultural research agenda in Uganda (Zawedde et al, 2012). A number of breakthroughs and high impact transformative innovations, including those developed through modern biotechnology, have been achieved by researchers with the aim of addressing some challenges in the agricultural sector (Zawedde et al, 2017). However, there is limited adoption of some of the technologies and agricultural innovations that have been released by NARO institutes. A study was conducted to identify how to enhance adoption of the relevant agricultural technologies and innovations that NARO has released for use by its clientele. The objectives for the study were to establish the causes of low adoption of the relevant agricultural technologies and innovation released by NARO; assess the different models of communication used by NARO to promote and support use of agricultural research outputs; and explore quasi-novel approaches of making agricultural research more visible and relevant to end-users.

\section{MATERIALS AND METHODS}

Uganda Biosciences Information Centre (UBIC), a NARO knowledge- and information-sharing hub has conducted surveys to establish the perception of stakeholders on NARO and the reasons why there is limited adoption of some technologies and products released by NARO. The latest survey was carried out in 2016. Structured questionnaire were used to establish whether farmers perceived NARO as a reliable sources of seed/planting materials and agricultural information, as well as understand their preferred sources of agricultural information. One hundred (100) farmers and farmers' associates were targeted, each, in four different farming systems: cassava production (in Soroti district); maize production (Kasese district); banana production (Bushenyi, district); cattle production (Kitgum district). The rating of likelihood used a 5-point scale, with $1=$ very likely and $5=$ very unlikely. In each case, participants were also asked to provide reasons for their rating. Data was analysed using SPSS statistical package 11.0/11.5 for Windows. Desk literature review and key informants were used to evaluate the communication models used by NARO since its inception, and to identify challenges in creating awareness for new technologies and products introduced by NARO.

\section{RESULTS AND DISCUSSION}

\section{Causes of low adoption of agricultural technologies released by NARO}

A total of 446 respondents participated in the survey used to establish the perception of stakeholders on NARO and the reasons why there is limited adoption of some technologies and products released by NARO. 


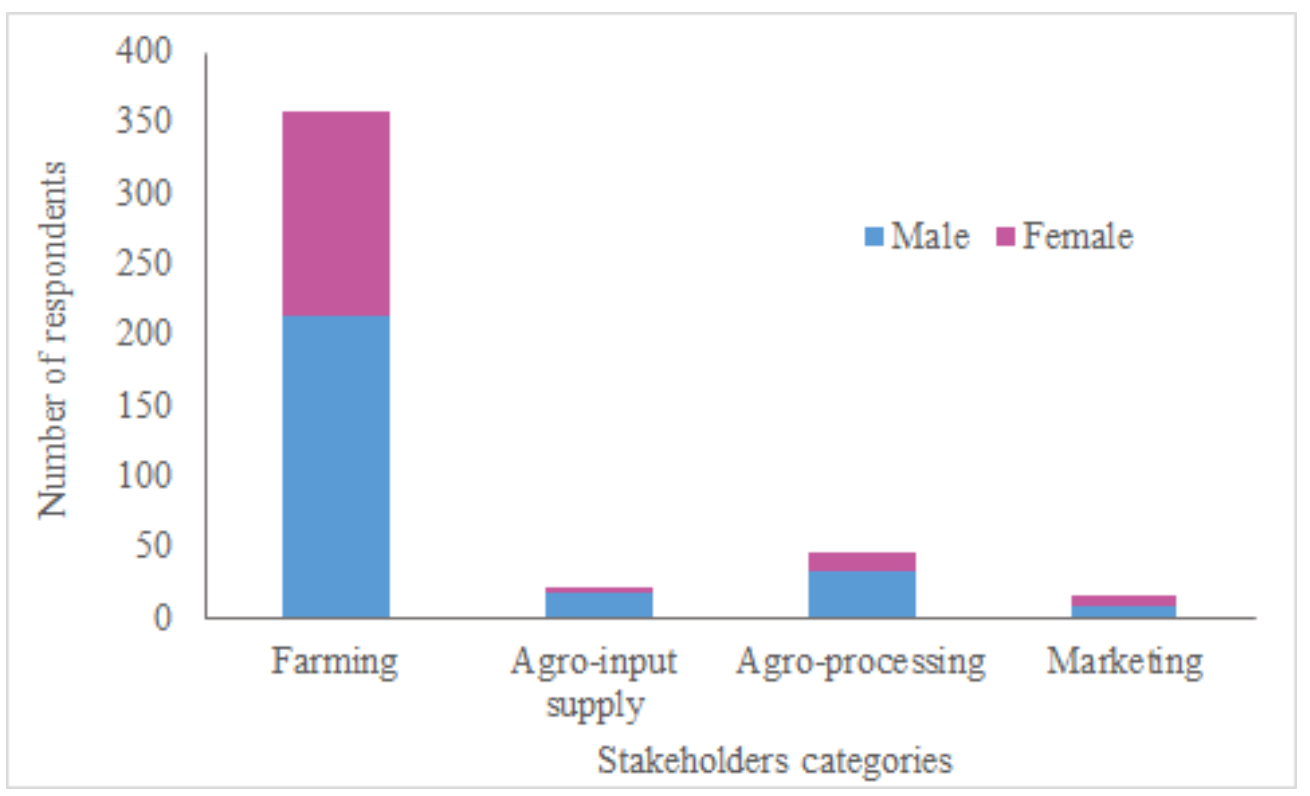

Figure 1. Respondents' categories by Districts and gender

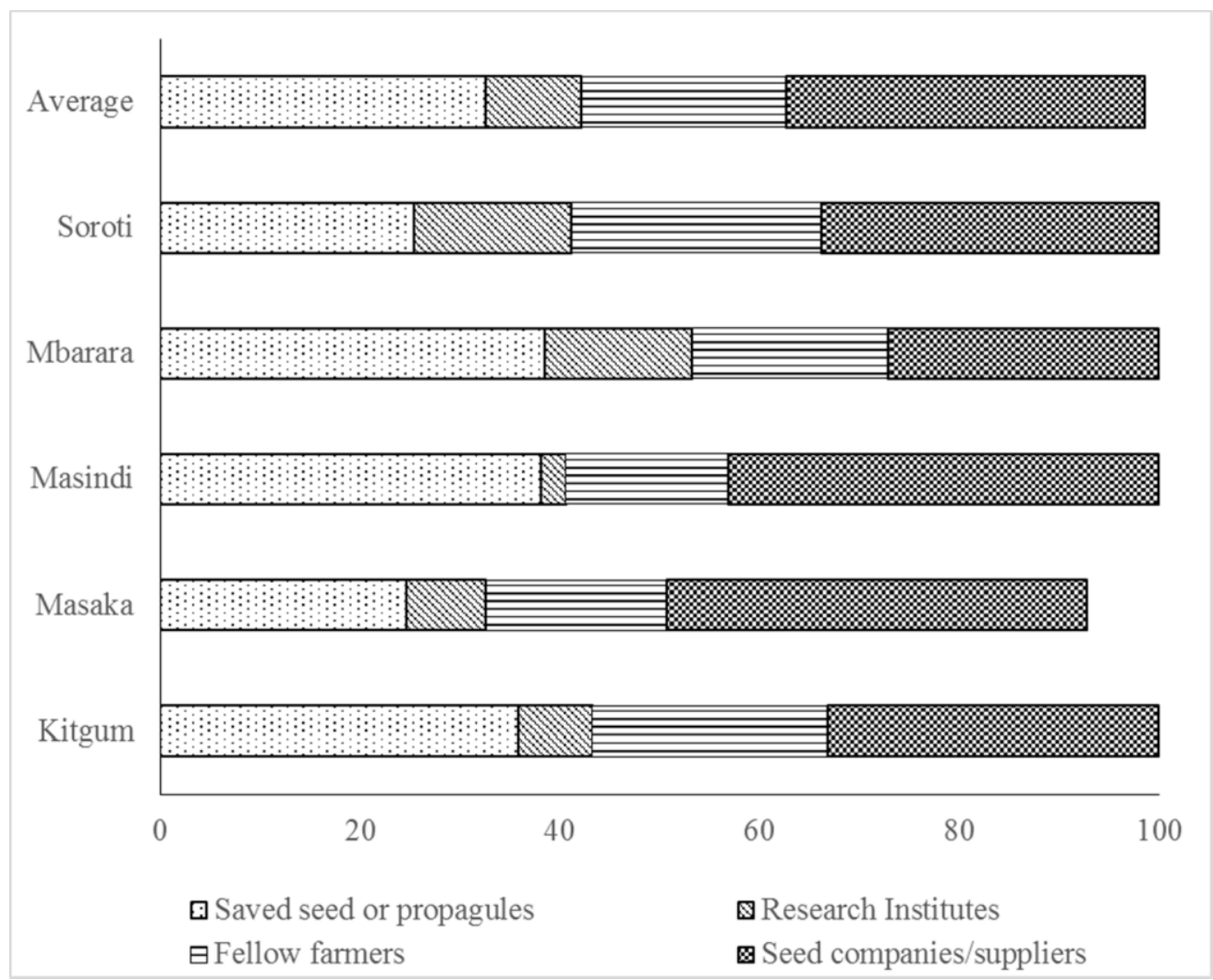

Figure 2. Percentage of the farmers, who responded that access seed or planting materials from different sources. 
Regarding the source of seed and planting materials, only $10 \%$ of the farmers indicated that they sourced their materials from research institutes (Figure 2). The common reasons why they do not access from research institutes included: lack of information about the varieties released by research institutes $(67 \%$ of the respondents), access challenges (44\%), especially for respondents from Masindi, Masaka and Soroti), and poor quality of products $(31 \%)$. Further inquiry from respondents that gave poor quality as a reason for not accessing planting materials from research institutes indicated that they were misinformed or they perceived that every product that varied taste, size and/or environmental adaptability, from what was considered to be normal, to be a product of the research institutes. This poor perception is a result of past experience due to misinformation or government policies that created disconnect between the end-users and the researchers.

When asked where respondents go to access information about agricultural technologies and farming, only $8 \%$ of the respondents indicated research institutes (Figure 3). This was mostly attributed to access challenges compared to other sources of information $(64 \%)$ and lack of trust $(35 \%)$.

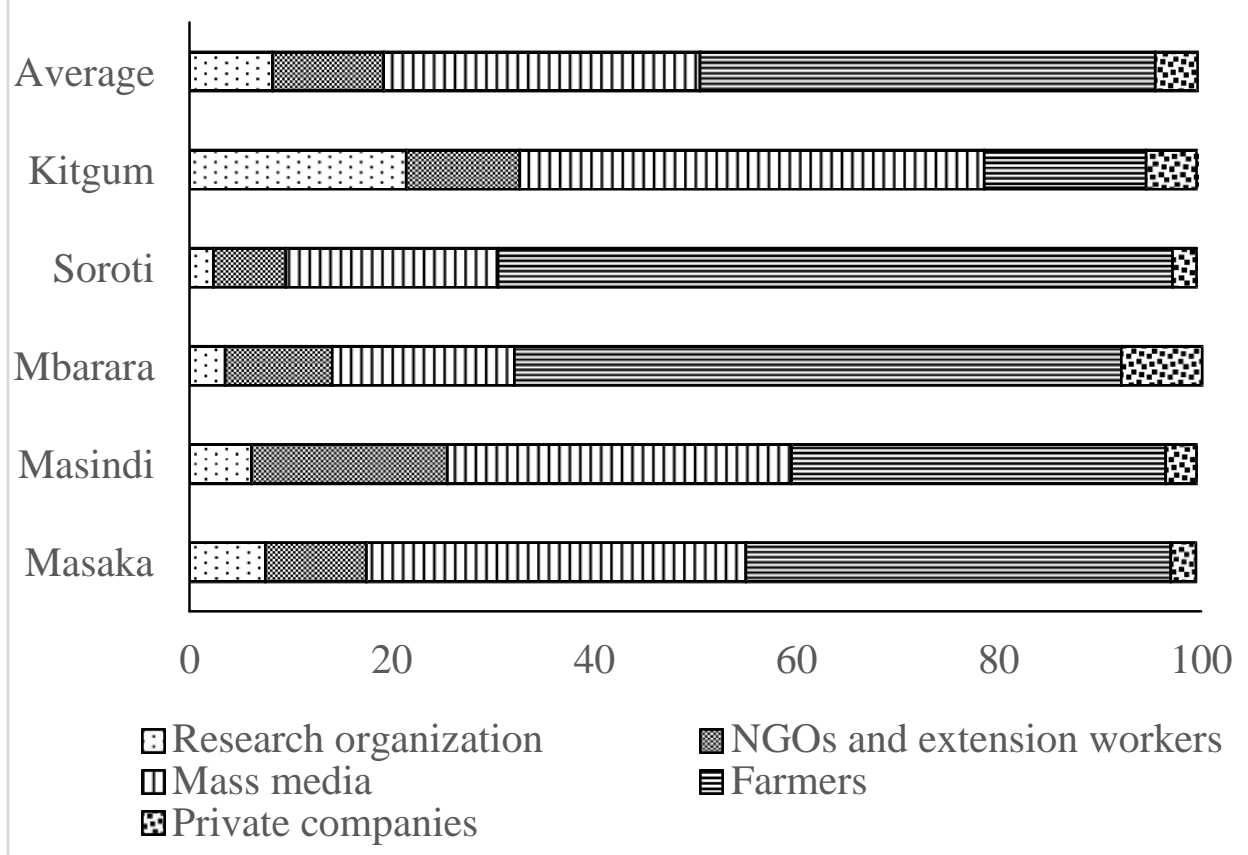

Figure 3. Percentage of respondents that access agricultural information from the different sources.

\section{Science communication models used to promote agricultural research outputs}

Agricultural extension services become a national priority in the 1920 s. Since then, the different models of science communication used to provide agricultural extension can be summarized as regulatory from 1920 to 1956, advisory from 1956 to 1971, dormancy from 1972 to 1981, and educational from 1982 to 1997 (Benin et al, 2011). In 1997, communication of new and improved agricultural technologies become 
a mandate of the Local Government as per the Local Government (LG) Act of 1992. This decentralized agricultural extension system focused on increasing agricultural productivity by sharing knowledge and information about application of modern technologies including improved seeds and agriculture mechanization without identifying farmers' needs (World Bank, 2012). This approach is considered a "deficit" model, since it prioritizes filling a deficit of knowledge, with a presumption that after fixing the deficit, everything will be 'better" (Lewenstein, 2003). This model faced challenges including limited adoption of technologies (Anselm and Taofeeq, 2010). This was attributed to the model being void of genuine farmer participation as actors in the research process. Instead, it relegated farmers to first-hand recipients of potentially abstract and prescribed solutions to agricultural problems. Often, research outcomes failed to completely reflect the people's needs and take into account their indigenous knowledge, practices, and perceptions which contributed to their failure to fully embrace the technologies (NARO, 2011).

As part of the Plan for Modernization of Agriculture (PMA, 2001) National Agricultural Advisory Services (NAADS) was created. NAADS is a semi autonomous public agency within the Ministry of Agriculture, Animal Industry, and Fisheries (MAAIF) in Uganda. NAADS is mandated to provide agricultural advisory and extension services by an Act of Parliament, the National Agricultural Advisory Services Act (2005). By way of communication and extension strategy, NAADS contracts two staff per sub-county to interact with, and give advice to, farmers and stakeholders in agriculture. With liberalisation of the agricultural sector, public extension services were shrunk; the number of extension staff reduced and less resources committed to knowledge transfer, in response to global trends (Rwamigisa et al., 2012). The contracts extension services used by NAADS were a demand-driven making this approach more of a contextual model. The contextual model acknowledges that individuals appreciate and process information better when the information is related to their previous experiences, and addresses personal needs (Lewenstein, 2003). This model increases increased offered farmers a higher level of ownership and accountability (Potts and Nagujja, 2007) compared to the deficit model. However, earlier phases of NAADs (2005-2012) faced challenges of ownership by its mother Ministry (MAAIF) and the local politicians that greatly affected its efficiency (Kjær and Joughin, 2012)

In a complimentary effort to make agricultural research more demandoriented, the Government of Uganda, in 2005, also enacted the National Agricultural Research Systems (NARS) Act that provided for NARO to increase its outreach activities and decentralize research (Potts and Nagujja, 2007). This resulted in the initiation of an Outreach and Partnership Initiative (OPI) for establishing Agricultural Research and Development Centres (ARDCs) located in different agroecological zones. The OPI used a more participatory model. The participatory model takes away some control of science from scientists, and politicians, and gives it to stakeholders groups through empowerment engagements (Lewenstein, 2003; Trends, 2008). OPI resulted in participatory research because farmers, extension service representative and private sector were involved in research activities, and promoting the new technologies. However, the past ten years have witnessed a slower adoption of new technologies despite the participatory model. This has been blamed on among, many other reasons, the failure to effectively create awareness for new technologies by NARO. Engagement with key informants identified some of the 
challenges in creating awareness for NARO technologies that are discussed below.

\section{Challenges in creating awareness for new technologies in agriculture}

\section{Perceived public mistrust of researchers}

Over the years, agricultural researchers have released thousands of new crop varieties in Uganda. However, sometimes a new variety that does not match known farming and consumption patterns is introduced for food security reasons. For example, close to 10 years ago, NARO released FHIA 17 and FHIA 25 Banana varieties to address the challenge of pests and diseases which was wreaking havoc across the country in the wake of drought, and looming prospect of a starving nation. Both varieties are from Honduras known to be tolerant to most pests and diseases, and more tolerant to dry conditions. It is capable of producing bigger bunches $(60-80 \mathrm{Kgs})$ compared to our local varieties (20-50 Kgs). However, NARO did not inform farmers that FHIA 17 was meant for consumption as a dessert while FHLA 25 was meant to produce juice. Thousands of desperate farmers planted the varieties hoping to consume them as cooked banana, but were distressed to discover that the varieties were not tasty in that form. The FHIA debacle remains a constant memory for farmers and increasingly perpetuates public bias against attempts by NARO to apply new agricultural technology.

\section{Small critical mass of communicators and trained journalists}

Agricultural reporting is a niche in journalism and communication but unfortunately, Uganda is yet to develop a critical mass of journalists with competence in writing about agricultural reporting, specifically on innovations such as biotechnology. According to the African Journalists Network for Agriculture (AJNA), a body for journalists who report agriculture, there are about only 25 journalists with relevant training, experience, and interest in reporting on biotechnology. Most of these have been trained in national and international programs such as the Biotechnology for Farming in Africa (B4FA) Fellowship programs which started in 2012 (B4FA, 2012).

\section{Absence of NARO communication node on new agricultural technologies}

Much work is going on in NARO, however, in the past there was no deliberate effort to centralise communication on new and improved agricultural technologies and products. Communication is done in a haphazard manner by singular projects managing their own communication functions; which creates duplication of messages and failure to reach out to some audience groups or to ensure that messages are accurately delivered to facilitate innovation adoption.

\section{Complex New Technologies}

The most controversial and complex agricultural innovation in Uganda currently is biotechnology, particularly is off shoot, genetic engineering. Due to the limited interaction between researchers and end users, activists against biotechnology have taken up the vacuum in the public knowledge space and used it extensively to denounce the technology; as scientists relied on the potential benefits of biotechnology to be sufficient enough to make it relevant. Arguments abound on the irrelevance of talking science-based solutions for heterogeneous societies. Those against the technology argue that Uganda should seek to generate home-grown solutions to native problems instead of importing whole technologies and exploring potential problems to be fixed. The debate on biotechnology has created a lot of environmental noise, laced with sensationalism that has contributed to the 
public distrusting researchers on the one hand and the latter actively taking on awareness campaigns and conducting communication outreach programs to provide factual information on biotechnology.

\section{The power of misinformation and the war between the professionals}

Communicating science with integrity has become a critical challenge in biotechnology communication in Uganda. Biotechnology is a fairly new concept in the public space in Uganda and has suffered from mixed interpretations and perceptions from groups of the public. Communication messages sensitizing the public about biotechnology in Uganda have been highly sensationalised and non-factual but communicated effectively and very believably. Also, the controversy on biotechnology has brought on board scientists who are pro- and antigenetic engineering methods. The failure to demonstrate consensus on biotechnology by scientists in different fields of specialization has resulted in increased public scepticism about agricultural research and new technologies.

\section{Recommended science communication models}

Cognizant of the growing gap between researchers and the Ugandan public, primarily farmers, NARO decided to intensify its outreach and communication efforts by establishing a Directorate for Agricultural Technology Promotion, DATP (Mbigidde et al., 2016). This effort aimed to complement the outreach through the National Agricultural Advisory Services (NAADS), using the participatory model. The current outreach efforts by NAADS and NARO's DATP aim to increasing focus on establishment of village-based model technology demonstrations that integrate local knowledge. This approach is a combination of the participatory model with the layexpertise model that integrates local knowledge in solving the problem (Lewenstein, 2003).

In 2013, NARO also established the Uganda Biosciences Information Centre (UBIC) as a hub for information- and knowledge-sharing on recent agricultural biosciences innovations and technologies in Uganda. UBIC was established under the auspices of the NextGen Cassava Project and is hosted at the National Crops Resources Research Institute (NaCRRI), which a NARO institute. UBIC has integrated various science communication models to build a sui generis model that understands the context in which communication about the given issues occurs; understands the relationship between the information the scientists want to share and what the target audience wants to hear; identifies and empowers relevant messengers including scientists and farmers to effectively deliver information to the target audience; identifies of strategic partners to maximize use of available resources to reach a wider audience; and uses various channels to obtain feedback from stakeholders regarding approaches used for information sharing and access to the new technologies. The model is expected to increase the public's confidence in researchers at public institutions, foster effective communication, while ensuring that the public's concerns and needs are articulated through open channels that will facilitate increased development and adoption agricultural technologies.

Effectiveness of the science communication models proposed above will be enhanced by willingness of the scientists and media practitioners to get involved in science communication, and increasing financial support by Government and development partners to strengthen the research-extension-farmers linkages. These models can be largely replicated to communicate science, technology and innovations in various sectors beyond agriculture. The key tenets used can also be 
applied to any aspect of science communication.

\section{ACKNOWLEDGEMENT}

The authors would like to express gratitude to the top management of National Crop Resources Research Institute (NaCRRI) and NARO for their guidance and support. We are grateful to the respondents from the five districts for making this study possible. We are very grateful for the financial support obtained through the NextGen Cassava Project.

\section{REFERENCES}

Anselm, A.E., and Taofeeq, A.A., 2010. Challenges of agricultural adaption to climate change in Nigeria: a Synthesis from the Literature. http:/ / factsreports.revues.org/index678. html [Accessed 18 January 2018].

B4FA, 2012. Media Fellowship Programme, Biosciences for Farming in Africa. http://b4fa.org/media-fellowshipprogramme/media-fellowships-uganda/ [Accessed 18 January 2018].

Benin, S., Nkonya, E., Okecho, G., Randriamamonjy, J., Kato, E., Lubadde G., and Kyotalimye M., 2011. Returns to spending on agricultural extension: the case of the National Agricultural Advisory Services (NAADS) program of Uganda. Agricultural Economics 42, 249-267.

Kjær, A.M., and Joughin, J., 2012. The reversal of agricultural reform in Uganda: Ownership and values, Policy and Society, 31:4, 319-330, DOI: 10.1016/j.polsoc.2012.09.004

Laker-Ojok, R., 1992. The Rate of Return to Agricultural Research in Uganda: The Case of Oilseeds and Maize@@ International Development Working Paper No. 42, Michigan State University, East Lansing, Michigan.
Lewenstein, B. V., 2003. Models of public communication of science and technology. 11pp.

Mbigidde, V.A., Kashaija, I.N., and Mugwanya, B.Z., 2016. Strengthening communication and knowledge management for increased agricultural productivity: A Ugandan case study. RUFORUM Working Document Series (ISSN 1607-9345) No. 14 (1): 385-393.

Mwangombe, W.A., and Sabiiti, E.N., 2001. Agricultural knowledge systems in the East African Region: lessons from the past 5 oyears and prospects for the future. Kilimo Trust http://www.kilimotrust.org/keynote.ph p [Accessed 31 January 2018].

NARO, 2011. Outreach and Partnership Initiatives: A strategy for decentralization and Institutional learning. Working Paper No.1. October, 2001. National Agricultural Research Organization, Uganda.

NARO, 2017. 25 Years of Unrivalled Agricultural Research Excellence. National Agricultural Research Organisation, Uganda, 17-10.

Potts, M.J., and Nagujja, S., 2007. A Review of Agriculture and Health Policies in Uganda with Implications for the Dissemination of Biofortified Crops. HarvestPlus: Washington, DC, USA, 2007.

Rwamigisa, P.B., Mangheni, M.N., and Birner, R., 2012. The challenge of reforming National Agricultural Extension Systems in Africa: The case of Uganda's policy reform process 19962011. Proceeding for International Conference on Innovations in Extension and Advisory Services

http://extension.cta.int/pages/Docume nts/Policy $\% 20$ Papers/4.Extension $\% 20$ a nd $\% 20$ Advisory $\% 20$ Policy $\% 20$ Reform/ CTA129\%20Extension\%20and\%20Advi sory $\% 20$ Policy $\% 20$ Reform_Rwamigisa_ 04.pdf [Accessed 12 November 2017].

Trench, B. (2008). Towards an analytical framework of science communication 
models. Communicating Science in Social

Contexts. Springer, Dordrecht. 119-135.

World Bank, 2012. Development Indicators for 2012. The World Bank, Washington DC, USA

http://data.worldbank.org/sites/default / files/wdi-2012-ebook.pdf [Accessed 04 February 2018].

Zawedde M. B., Akile S., Nakabuye S., Sengooba T., 2012. Policies \& Laws of Relevance to Regulation of Agricultural Biotechnology in Uganda. Policy Brief No. 3, 2012. Uganda Biotechnology and Biosafety Consortium, 4pp.

Zawedde M. B., G. Gumisiriza, A. Tibasaaga, N. Mugwanya, J. Muhumuza, 2017. Uganda's Top Ten Facts about Biotechnology and Biosafety by 2016. UBIC Handbook for Policy Makers, 16 pp. 